\title{
Dual tumor-targeted poly(lactic-co-glycolic acid)-polyethylene glycol-folic acid nanoparticles: a novel biodegradable nanocarrier for secure and efficient antitumor drug delivery
}

\author{
This article was published in the following Dove Press journal: \\ International Journal of Nanomedicine \\ 10 August 2017 \\ Number of times this article has been viewed
}

\section{Jia Chen ${ }^{1,2, *}$ \\ Qi Wu',* \\ Li Luo' \\ Yi Wang' \\ Yuan Zhong' \\ Han-Bin Dai' \\ Da Sun ${ }^{1,3}$ \\ Mao-Ling Luo ${ }^{4}$ \\ Wei Wu' \\ Gui-Xue Wang'}

'Key Laboratory for Biorheological Science and Technology, Ministry of Education, State and Local Joint Engineering Laboratory for Vascular Implants, Bioengineering College, Chongqing University, Chongqing, ${ }^{2}$ Institute of Laboratory Animals, Sichuan Academy of Medical Science, Sichuan Provincial People's Hospital, Chengdu, ${ }^{3}$ Institute of Life Sciences, Wenzhou University, Wenzhou, ${ }^{4}$ School of Medicine, Wuhan University, Wuhan, China

*These authors contributed equally to this work
Correspondence: Wei Wu; Gui-Xue Wang Bioengineering College, Chongqing University, 174 Shazheng Street, Shapingba Qu, Chongqing, 400030, China Email david2015@cqu.edu.cn; guixue_wang@I26.com

\begin{abstract}
Further specific target-ability development of biodegradable nanocarriers is extremely important to promote their security and efficiency in antitumor drug-delivery applications. In this study, a facilely prepared poly(lactic-co-glycolic acid) (PLGA)-polyethylene glycol (PEG)-folic acid (FA) copolymer was able to self-assemble into nanoparticles with favorable hydrodynamic diameters of around $100 \mathrm{~nm}$ and negative surface charge in aqueous solution, which was expected to enhance intracellular antitumor drug delivery by advanced dual tumor-target effects, ie, enhanced permeability and retention induced the passive target, and FA mediated the positive target. Fluorescence-activated cell-sorting and confocal laser-scanning microscopy results confirmed that doxorubicin (model drug) loaded into PLGA-PEG-FA nanoparticles was able to be delivered efficiently into tumor cells and accumulated at nuclei. In addition, all hemolysis, 3-(4,5-dimethylthiazol-2-yl)-5-(3-carboxymethoxyphenyl)-2-(4-sulfophenyl)-2H-tetrazolium, and zebrafish-development experiments demonstrated that PLGA-PEG-FA nanoparticles were biocompatible and secure for biomedical applications, even at high polymer concentration $(0.1 \mathrm{mg} / \mathrm{mL})$, both in vitro and in vivo. Therefore, PLGA-PEG-FA nanoparticles provide a feasible controlled-release platform for secure and efficient antitumor drug delivery.
\end{abstract}

Keywords: tumor target, biodegradable nanoparticle, security, efficient, drug delivery, tumor therapy

\section{Introduction}

Security and efficiency are essential criteria in drug-delivery carrier design. In the last few decades, rapid development of biodegradable polymeric carriers has attracted considerable attention, because of their versatile functional construction and biocompatibility for wide applications in biomedicine, such as drug delivery, gene delivery, tissue engineering, diagnosis, antibacterial/antifouling properties, and medical devices. ${ }^{1-9}$ With regard to security, with rational design, biodegradable polymeric carriers are able to degrade into friendly biological catabolites, which is particularly important to reduce systemic cytotoxicity caused by the carrier. On the other hand, simplex biodegradable carriers cannot always meet rigorous demands, owing to the extremely hostile and complex environments in vivo. Therefore, in the interests of efficiency, further development of sophisticated carriers with sufficient target capability can not only promote therapeutic efficiency but also reduce drugs' systemic side effects. ${ }^{10-15}$ The targeting ability of carriers is as important as their biodegradability, and both are essential for design of feasible candidate agents for potential clinical applications. 
For antitumor purposes, owing to the incomplete endothelial lining and basement membranes of the tumor vascular system leading to leaky vascular structure, the nanosize carrier (usually from several nanometers to $200 \mathrm{~nm}$ ) favors extravasating and accumulating within tumor tissues through the enhanced permeability and retention (EPR) effect in the vast majority of solid tumors. As such, nanocarriers inherently possess the passive target function to enhance antitumor therapy. ${ }^{16-20}$ However, it is notable that passive target efficiency is relatively low and limited in terms of providing sufficient therapy efficacy for significant acceleration of tumor-cell apoptosis. By contrast, specific overexpressed antigens or receptors on tumor-cell surfaces have been widely exploited to help in nanocarrier targeted delivery to tumor locations by modifying paired ligands or antibodies on carrier surfaces. The receptor-mediated uptake pathway, a positive target strategy, is beneficial in promoting subsequent targeted recognition and internalization by tumor cells. ${ }^{21}$ Folic acid (FA) is one representative of the most used and efficient receptors to enhance antitumor targeting through pairing of overexpression of FA receptors on various tumor-cell surfaces. For example, Jiang et al constructed target-ligand FA and cell-penetrating octaarginine-coupled gene vectors, which were of benefit in promoting targeted antitumor therapy by enhanced FA-mediated location and endocytosis. ${ }^{22}$ Lee et al developed FA-secondary lymphoid tissue chemokineupconversion fluorescent nanoparticles. In the contrast test, the FA-conjugated nanoparticles showed specific targeting ability to FA receptors expressing an ovarian carcinoma cell line, and exhibited no significant cytotoxicity effects. ${ }^{23}$ Furthermore, based on the FA endowing tumor-targeting properties, a large number of FA-conjugated nanosystems have also been exploited for specific tumor diagnosis and imaging. ${ }^{24-27}$ With the synergistic effects of nanosizemediated passive target and FA-mediated positive target, FA-modified nanocarriers are expected to be a great candidate for improving antitumor efficiency and biocompatibility for potential clinic usage.

The US Food and Drug Administration-approved poly(lactic-co-glycolic) acid (PLGA) is an excellently biodegradable copolymer. As the most attractive and efficient polymeric nanocarrier, PLGA nanoparticles are widely used in clinical applications. ${ }^{28-32}$ Additionally, polyethylene glycolated (PEGylated) PLGA nanoparticles have been developed to improve bioavailability and antitumor targeting further. ${ }^{28,33,34}$ In other words, besides the hydrophobic region of PLGA being efficient in hydrophobic drug encapsulation, the hydration on the hydrophilic PEG corona can further prevent nanocarriers from aspecific protein adsorption and reticuloendothelial system clearance for prolonging blood circulation in vivo. ${ }^{35-39}$ Therefore, PEGylated PLGA nanoparticles are advanced platforms to enhance targeted antitumor drug delivery.

In this study, the tumor target copolymer PLGA-PEG-FA was successfully synthesized by a facile one-step reaction. In aqueous solution, PLGA-PEG-FA was able to self-assemble into nanoparticles with a PLGA core and PEG corona with FA exposed on the surface. PLGA-PEG-FA efficiently solubilized the hydrophobic model drug - desalted doxorubicin (Dox) - by encapsulating it in the hydrophobic region of PLGA for targeted antitumor drug delivery. Dox-loaded PLGA-PEG-FA (PLGA-PEG-FA@Dox) nanoparticles were specifically delivered to tumor locations by EPR and subsequently efficiently endocytosed by tumor cells, because of FA-mediated coupling with overexpressed FA receptors on tumor-cell surfaces. Benefiting from the enhanced antitumor drug-delivery efficiency by the dual-target effects, desirable intracellular Dox release is capable of providing sufficient therapeutic concentration to induce tumor-cell apoptosis rapidly (Scheme 1). In this proof of concept, PLGA-PEG-FA@ Dox nanoparticles exhibited uniform spherical morphology with an average hydrodynamic diameter of $136.5 \mathrm{~nm}$, confirming by dynamic light scattering (DLS) and transmission electron microscopy (TEM). According to confocal laserscanning microscopy (CLSM) and fluorescence-activated cell-sorting (FACS) results, more Dox-fluorescence overlap with tumor-cell nuclei revealed that PLGA-PEG-FA@Dox nanoparticles exhibited enhanced efficacy for intracellular drug delivery. In addition, in cytotoxicity studies, PLGAPEG-FA nanoparticles also showed low cytotoxicity to cells and zebrafish. Toxicity results demonstrated that PLGA-PEG-FA is well biocompatible for potential in vivo applications. Therefore, PLGA-PEG-FA nanoparticles are a feasible candidate for secure and efficient targeted antitumor drug delivery in potential clinical applications.

\section{Materials and methods Materials}

FA-PEG-NH $\mathrm{N}_{2}>95 \%$ (PEG molecular weight [MW] $2 \mathrm{kDa}$ ) was purchased from Hunan Huaten Pharma (Changsha, China). Carboxyl-terminated 50:50 PLGA (MW $90 \mathrm{kDa}$ ) and Dox $\cdot \mathrm{HCl}>98 \%$ were obtained from Melone Biotechnology (Dalian, China). Dicyclohexylcarbodiimide (DCC; 98\%) and 4-dimethylaminopyridine (DMAP; 99\%) were purchased from Aladdin Biological Technology (Xi'an, China). Dimethyl sulfoxide (DMSO) was purchased from 


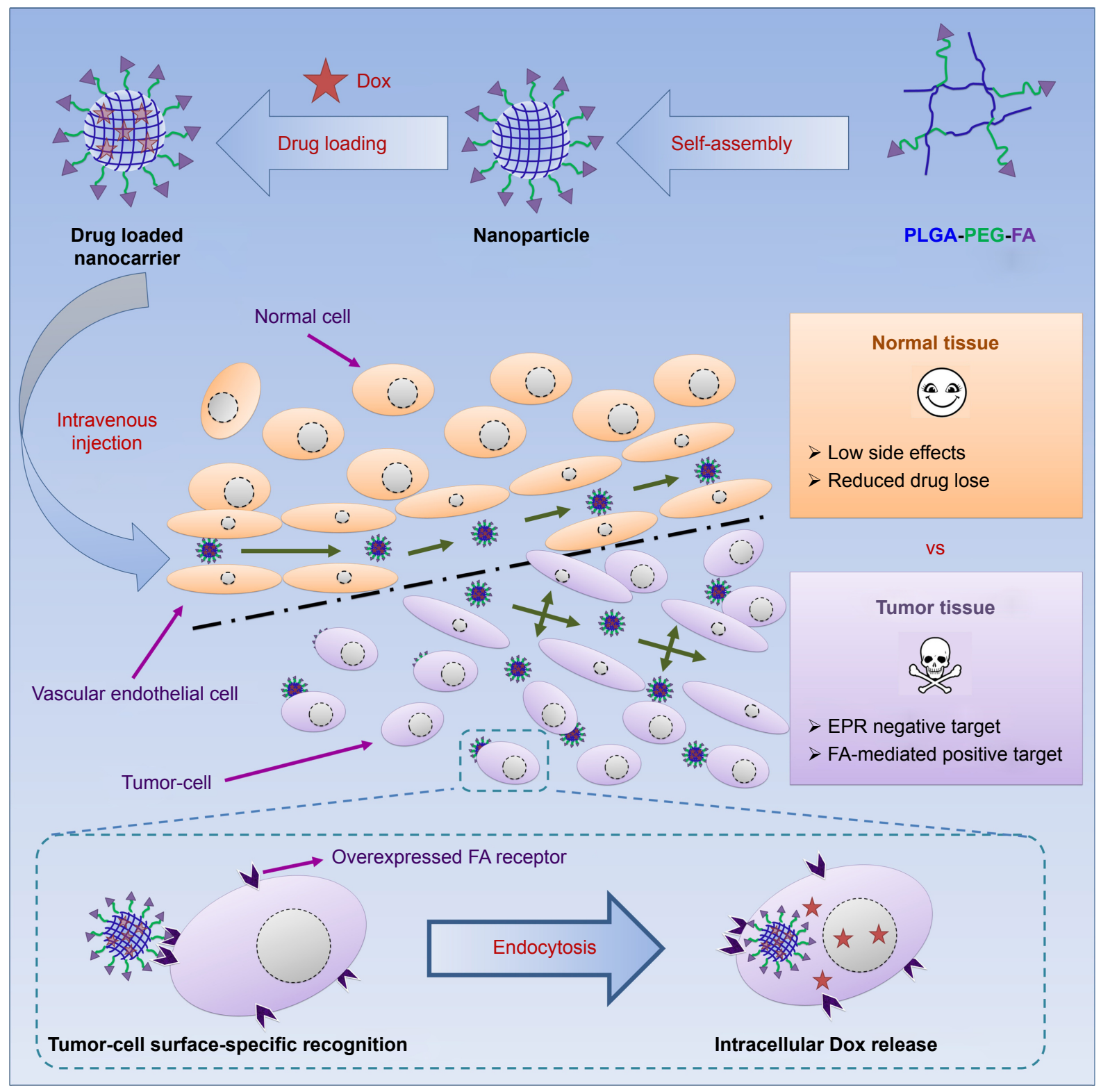

Scheme I Illustration of dual tumor-targeted PLGA-PEG-FA nanoparticles for secure and efficient antitumor drug delivery.

Abbreviations: PLGA, poly(lactic-co-glycolic acid); PEG, polyethylene glycol; FA, folic acid; Dox, doxorubicin; EPR, enhanced permeability and retention.

Bodi Chemical Holding (Tianjin, China) and used after dehydration. Desalted Dox was obtained using triethylamine as previously reported. ${ }^{40-42} \mathrm{HeLa}$ cells were purchased commercially from the Cell Bank of the Chinese Academy of Sciences (Shanghai, China). All other reagents without further instruction were used as received. Ultrapure water with a resistivity of $18.2 \mathrm{M}$ was used throughout.

\section{Synthesis and characterization of PLGA-PEG-FA}

For positive target functionalization, carboxyl groups of PLGA and the amine group of FA-PEG-NH ${ }_{2}$ were chemically conjugated through amidation. Synthesis of PLGA-PEG-FA was achieved by PLGA ( $900 \mathrm{mg}, 0.01 \mathrm{mmol}$ ), FA-PEG-NH (49 mg, $0.02 \mathrm{mmol}$ ), DCC (41 mg, $0.2 \mathrm{mmol}$ ), and DMAP (3 mg, $0.02 \mathrm{mmol}$ ) being dissolved in DMSO (5 mL). The mixture was stirred at $40^{\circ} \mathrm{C}$ for 48 hours. After dilution with $40 \mathrm{~mL}$ of ultrapure water, the resulting solution was dialyzed against ultrapure water to remove solvent and unreacted FA-PEG-NH ${ }_{2}$ (MW cutoff [MWCO] 8,000-14,000 Da). PLGA-PEG-FA was obtained as a slight yellow powder through lyophilization from the residual solution (yield $817 \mathrm{mg}, 88.3 \%$ ). To confirm PLGA-PEG-FA modification, proton nuclear magnetic resonance ( ${ }^{1} \mathrm{H}$ NMR) spectra were 
recorded with a Bruker Avance (AVII-400; Bruker Optik $\mathrm{GmbH}$, Ettlingen, Germany) at $400 \mathrm{MHz}$ in DMSO-d $\mathrm{d}_{6}$ using tetramethylsilane as an internal standard.

\section{Preparation and characterization of nanoparticles}

Nanoparticles were prepared using dialysis. After PLGAPEG-FA or PLGA $(100 \mathrm{mg})$ had absolutely dissolved into DMSO (5 mL), ultrapure water was added dropwise. The mixture was stirred for 3 hours. The final solution was dialyzed against ultrapure water to remove DMSO. The resulting PLGA-PEG-FA nanoparticle solution was passed through a $0.45 \mu \mathrm{m}$ filter and stored at $4^{\circ} \mathrm{C}$ for further measurements. Preparation of Dox-loaded nanoparticles used the same operation, except adding a determined amount of desalted Dox into the DMSO mixture before ultrapure water was added.

Hydrodynamic diameter, $\zeta$-potential, and size distribution of nanoparticles were measured by DLS (Zetasizer Nano ZS 90; Malvern Instruments, Malvern, UK) with a helium-neon laser $(\lambda=633 \mathrm{~nm})$ at a scattering angle of $90^{\circ}$. The final concentration of PLGA-PEG-FA or PLGA was fixed at $0.5 \mathrm{mg} / \mathrm{mL}$. Before transferred into a sample cuvette, the polymer solution was subjected to ultrasonic treatment. Each sample was measured three times at $37^{\circ} \mathrm{C}$, and hydrodynamic diameter obtained from the average of three measurements $(\mathrm{n}=3)$.

Morphologies of nanoparticles were observed by TEM (H-600; Hitachi, Tokyo, Japan) at an accelerating voltage of $75 \mathrm{kV}$. A drop of prepared copolymer solution $(0.5 \mathrm{mg} / \mathrm{mL})$ was deposited on a carbon-coated copper grid (200 meshes). After thorough air-drying, samples were photographed.

\section{Hemolytic assay}

Fresh whole blood obtained from the New Zealand White rabbit was mixed with the anticoagulant ethylenediaminetetraacetic acid dipotassium salt and diluted with commercial saline $(0.9 \% \mathrm{NaCl})$. The commercial saline and ultrapure water were used as negative control and positive control, respectively. Briefly, samples were added to the saline to prepare polymeric samples with different concentrations. The mixtures were incubated at $37^{\circ} \mathrm{C}$ for 30 minutes. After $60 \mu \mathrm{L}$ of the diluted whole blood had been added, the mixtures were further incubated at $37^{\circ} \mathrm{C}$ for 1 hour. Finally, the absorbance of the centrifuged supernatant was measured at $545 \mathrm{~nm}$ by ultraviolet-visible spectrophotometry (DU-800; Beckman Coulter, Brea, CA, USA). The hemolysis ratio (\%) was calculated thus:

$$
\frac{O D_{T}-O D_{N C}}{O D_{P C}-O D_{N C}} \times 100 \%
$$

where $O D_{T}, O D_{N C}$, and $O D_{P C}$ were the mean absorbance of the tested sample, negative control, and positive control, respectively.

\section{Quantification of loaded Dox}

After the Dox-loaded lyophilized samples had been redissolved in DMSO, Dox-loaded content was detected by fluorescence-correlate spectrophotometry (LS55; PerkinElmer, Waltham, MA, USA) using excitation wavelength, emission wavelength, and slit at 480, 555, and $3 \mathrm{~nm}$, respectively. Subsequently, according to the established calibration curve, Dox-loading efficiency (LE) and -entrapment efficiency (EE) were calculated using Equations 2 and 3:

$$
\begin{gathered}
\text { Loading efficiency }(\%)=\frac{M_{\text {Dox }}}{M_{\text {Polymer }}+M_{\text {Dox }}} \times 100 \% \\
\text { Encapsulation efficiency }(\%)=\frac{M_{\text {Dox }}}{M_{\text {added }}} \times 100 \%
\end{gathered}
$$

where $M_{\text {Dox }}$ was the mass of Dox loaded in nanoparticles, $M_{\text {Polymer }}$ the mass of polymer in formulations, and $M_{\text {added }}$ the mass of added Dox.

\section{In vitro drug-release behavior}

The drug-release behavior of Dox-loaded nanoparticles was handled in phosphate buffer saline (PBS, 0.01 M). Dox-loaded nanoparticle solution $(10 \mathrm{~mL}, 0.5 \mathrm{mg} / \mathrm{mL})$ was added to dialysis tubes (MWCO 3,500). Subsequently, dialysis tubes were immersed in $90 \mathrm{~mL}$ PBS to incubate at $37^{\circ} \mathrm{C}$ in an incubator shaker $(100 \mathrm{rpm})$. At predetermined time intervals, the external drug-released buffers of dialysis bags were collected and replaced by equal volume of fresh PBS. The concentration of released Dox was detected using fluorescence-correlate spectrophotometry (LS55) using excitation wavelength, emission wavelength, and slit at 480,555 , and $3 \mathrm{~nm}$, respectively. The cumulative amount of released Dox was calculated according to a preestablished calibration curve. Finally, Dox content released from nanoparticles was plotted against time.

\section{Intracellular trafficking}

Intracellular trafficking behavior of Dox-loaded nanoparticles was determined by CLSM (TCRS SP5; Leica, Germany) using HeLa cells. In brief, HeLa cells in culture media (DMEM) were incubated for 1 day in specialized cell culture dishes with $\sim 70 \%$ cell confluence $\left(\sim 2 \times 10^{4}\right.$ cells $/$ dish $)$. Then, the culture medium was replaced by fresh medium containing Dox-loaded nanoparticles (filtered through $0.2 \mu \mathrm{m}$ syringe-driven filters before use, $0.5 \mathrm{mg} / \mathrm{mL}$ ). After 4 and 
24 hours, the culture medium was removed and cells washed three times with PBS ( $\mathrm{pH} 7.4)$. Then, cells were fixed with $4 \mathrm{w} / \mathrm{v} \%$ formaldehyde at $4^{\circ} \mathrm{C}$ for 20 minutes. Cell skeletons were stained with commercial fluorescein isothiocyanate (FITC)-labeled phalloidin $(0.5 \mathrm{mg} / \mathrm{mL})$ for 40 minutes. After another three washes using PBS, cell nuclei were stained with Hoechst $33342(5 \mu \mathrm{g} / \mathrm{mL})$ for an additional 10 minutes. Finally, stained samples were subjected to fluorescence imaging by CLSM. Excitation/emission was fixed at 480/555 nm, 495/513 nm, and 352/504 nm for Dox, phalloidin-FITC, and Hoechst 33342, respectively. The only difference in the FA receptor-blocked control group was for pretreated HeLa cells using dissolved FA for 4 hours before HeLa-cell coculture with PLGA-PEG-FA@Dox nanoparticles.

\section{Cellular uptake study}

Internalization efficiency of the loaded nanoparticles was evaluated using HeLa cells by FACS (BD Biosciences, San Jose, CA, USA). HeLa cells were seeded in six-well plates at $10^{6}$ cells/well and incubated at $37^{\circ} \mathrm{C}$ for 24 hours. Then, the culture medium was replaced by fresh medium containing Dox-loaded nanoparticles (filtered through $0.2 \mu \mathrm{m}$ syringedriven filters before use, $0.5 \mathrm{mg} / \mathrm{mL}$ ) to coculture for 4 hours. Thereafter, cells were harvested with trypsin by centrifugation, washed three times with PBS, fixed with 70\% alcohol for 2 hours, and rewashed three times with PBS. Dox uptake was examined by analyzing Dox-fluorescence intensity at $488 \mathrm{~nm}$ using FACS. The FA receptor-blocked PLGA-PEG-FA@ Dox control group was treated as previously described.

\section{Cytotoxicity studies}

The in vitro cytotoxic behavior of nanoparticles was evaluated by standard MTS assay using HeLa cells. Polymer-free DMEM-cultured HeLa cells were used as control. In brief, the cells were cultured in DMEM at $37^{\circ} \mathrm{C}$ in an atmosphere of $5 \% \mathrm{CO}_{2}$ and $95 \%$ relative humidity. Growing cells $\left(5 \times 10^{3}\right.$ cells/well $)$ were seeded on a 96 -well microplate (Nunc, Wiesbaden, Germany) and incubated in $100 \mu \mathrm{L}$ DMEM/well for 24 hours. Then, fresh culture medium containing serial dilutions of polymeric nanoparticles was used to treat cells for 48 hours. After that, cells were incubated with $20 \mu \mathrm{L}$ of MTS stock solution in PBS $(0.5 \mathrm{mg} / \mathrm{mL})$ in each well for 2 hours. Absorbance at $490 \mathrm{~nm}$ was measured by a microplate reader $(\mathrm{EL} \times 800$, BioTek Instruments Inc., MA, USA). Relative cell viability (\%) was calculated thus:

$$
\frac{A_{\text {test }}}{A_{\text {control }}} \times 100 \%
$$

where $A_{\text {test }}$ and $A_{\text {control }}$ were the mean absorbance value of the treatment group and the mean absorbance value of the control group (without polymer), respectively.

\section{Zebrafish development}

Guide for Chinese Animal Care and Use Committee standards were followed for animal housing and surgical procedures. All procedures were done in accordance with protocols approved by the Laboratory Animal Welfare and Ethics Committee of the Third Military Medical University before commencement of the animal studies. Fertilized eggs of AB wild-type zebrafish were collected within 6 hours postfertilization (hpf). For experiments, healthy embryos in the same development stage were selected and randomly placed in 24-well culture plates, with ten embryos each well $(n=3)$. At $12 \mathrm{hpf}$, embryos were incubated with $0.033,0.05$, and $0.1 \mathrm{mg} / \mathrm{mL}$ of polymeric nanoparticles in distilled water. Embryos in wells with distilled water only were used as blank control. The viability and malformation of embryos were examined under stereomicroscopy (Stemi 2000-C; Carl Zeiss Meditec AG, Jena, Germany) at 24 and $48 \mathrm{hpf}$, respectively. After anesthesia with $100 \mu \mathrm{L}$ of tricaine $(4 \mathrm{mg} / \mathrm{mL}$; SigmaAldrich, St Louis, MO, USA), viability and malformation of the hatched zebrafish larvae were examined at $96 \mathrm{hpf}$.

\section{Results and discussion Synthesis and characterization of PLGA-PEG-FA}

Functional modification of biodegradable PLGA polymers is an important strategy to construct rational and versatile carriers to cope with the extremely hostile and complex environments in vivo. PEGylated and FA-modified PLGA (PLGA-PEG-FA) was facilely synthesized by one-step amidation (Figure 1). Compared with the ${ }^{1} \mathrm{H}$ NMR spectrum of unmodified PLGA, the new presence of characteristic peaks at 3.51 and 6.62-8.65 ppm were respectively ascribed to the resonance of methylene groups in PEG and partial hydrogen groups in FA (Figure S1), which confirmed the successful synthesis of PLGA-PEG-FA.

\section{Physicochemical characterization of PLGA-PEG-FA self-assembly}

With regard to hydrophilicity-hydrophobicity balance, PLGA and PLGA-PEG-FA are both able to self-assemble into nanoparticles with favorable thermodynamic stability in aqueous solution. As such, these nanoparticles are still feasible for biomedical drug-delivery applications, even under extremely high-dilution conditions. ${ }^{16,42-48}$ In this study, copolymer self-assembled nanoparticles were prepared using dialysis. 


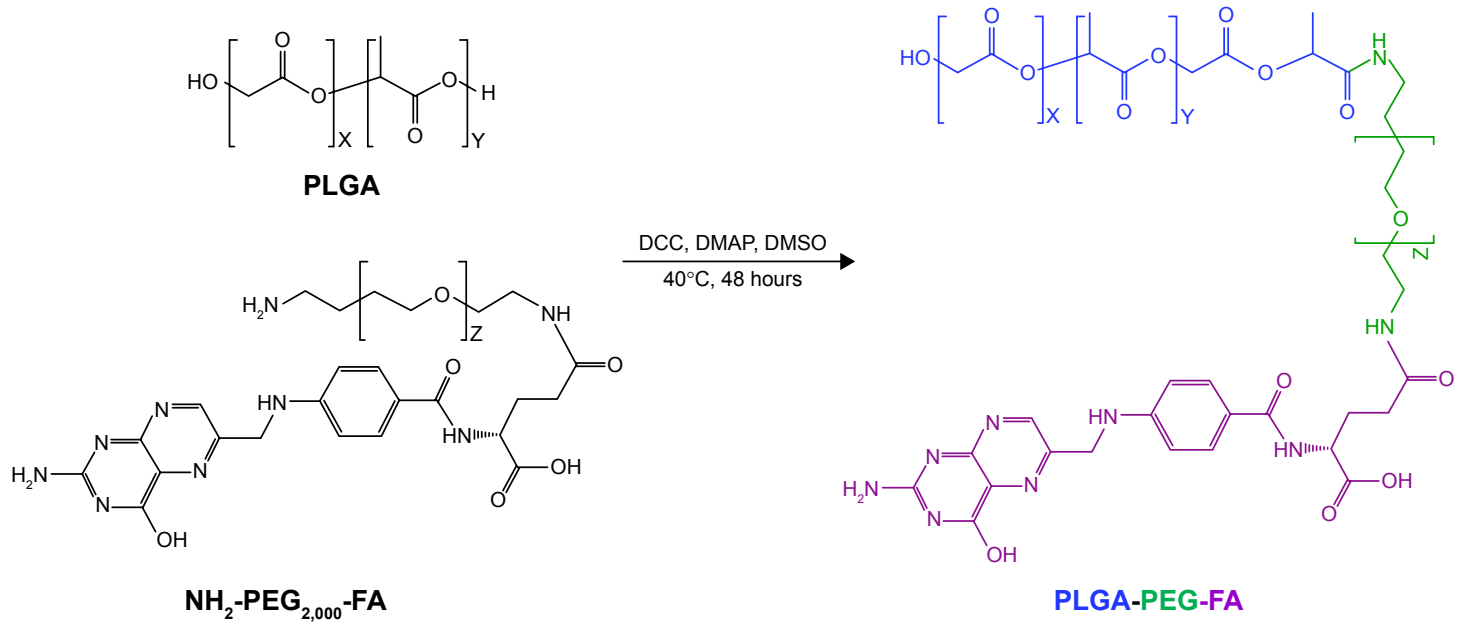

Figure I Synthetic route of PLGA-PEG-FA.

Abbreviations: PLGA, poly(lactic-co-glycolic acid); PEG, polyethylene glycol; FA, folic acid; Dox, doxorubicin; DCC, dicyclohexylcarbodiimide; DMAP, dimethylaminopyridine; DMSO, dimethyl sulfoxide.

According to DLS results (Figures 2A and S2), hydrodynamic diameter/surface potential of PLGA and PLGA-PEG-FA were $82.5 \pm 4.1 \mathrm{~nm} /-27.2 \pm 1.2 \mathrm{mV}$ and $130.8 \pm 3.4 \mathrm{~nm} /-$ $25.3 \pm 0.7 \mathrm{mV}$, respectively. Interestingly, the slight increase in PLGA-PEG-FA hydrodynamic diameter and slight reduction of PLGA-PEG-FA surface potential may be ascribed to better hydrophilic ability and the surface charge-shielding effect caused by the modified hydrophilic PEG outermost layer, respectively. In addition, the hydrodynamic diameter/ surface potential of Dox-loaded nanoparticles PLGA@Dox and PLGA-PEG-FA@Dox were 124.8 $\pm 2.4 \mathrm{~nm} /-23 \pm 0.4 \mathrm{mV}$ and $136.5 \pm 4.3 \mathrm{~nm} /-23.3 \pm 0.5 \mathrm{mV}$, respectively. Compared with the blank nanoparticles, the slight hydrodynamic diameter increase and slight surface-potential reduction of Dox-loaded nanoparticles may have been caused by hydrophobicity and the positively charged Dox group, which also infers Dox loading was driven by not only physical encapsulation effects in the hydrophobic region of PLGA nanoparticles but also electrostatic interaction on the negatively charged surface of PLGA nanoparticles. The multi-efforts of physical
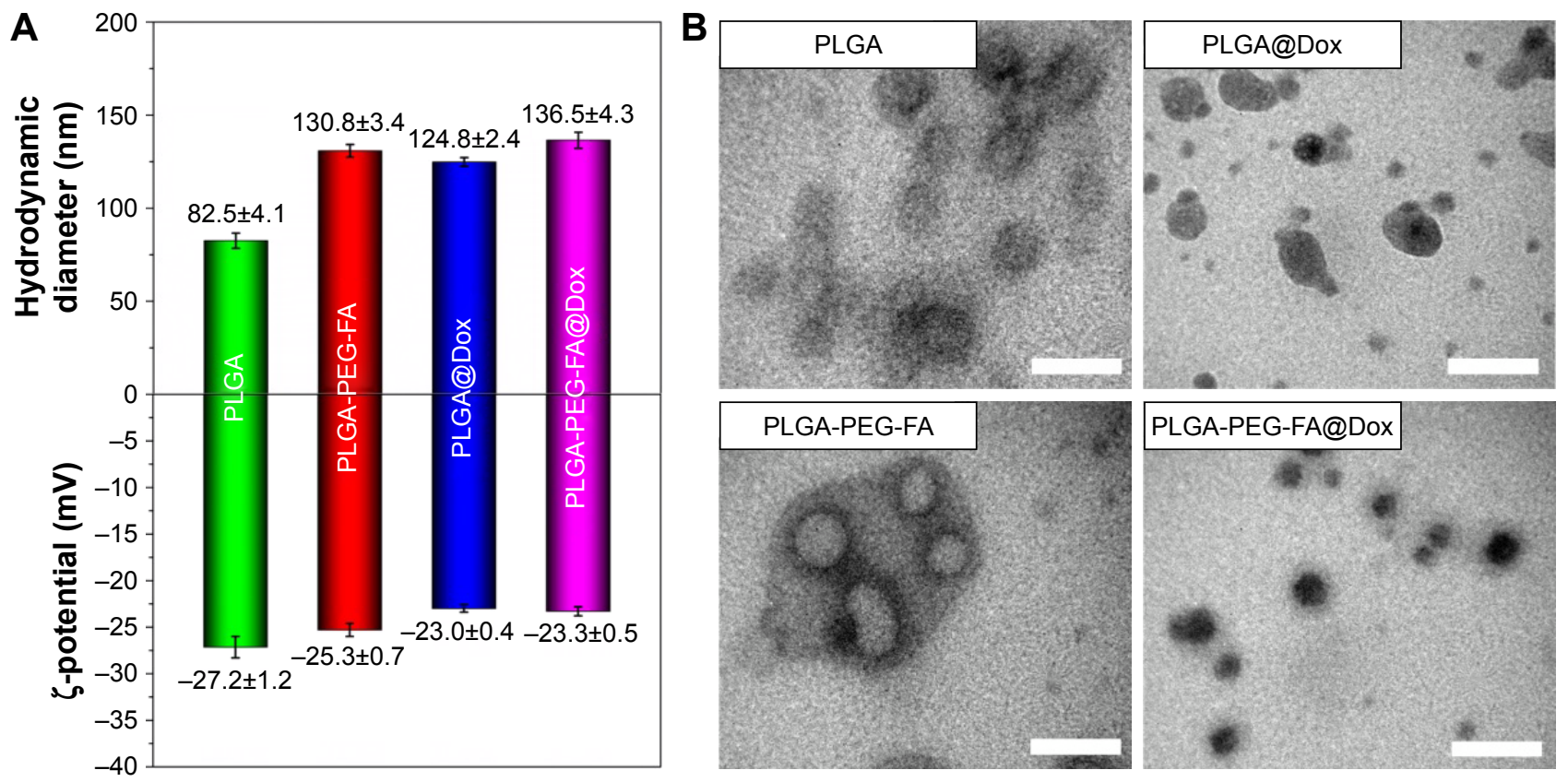

Figure 2 (A) Average hydrodynamic diameter and $\zeta$-potential; (B) TEM of samples at a concentration of $0.5 \mathrm{mg} / \mathrm{mL}$.

Note: TEM scale bars in micrographs are $200 \mathrm{~nm}$.

Abbreviations: TEM, transmission electron microscopy; PLGA, poly(lactic-co-glycolic acid); PEG, polyethylene glycol; FA, folic acid; Dox, doxorubicin. 
encapsulation and electrostatic interaction interacted drug loading in carriers are expected to prevent undesirable premature drug loss during the drug-delivery process. The favorable hydrodynamic diameter (around $100 \mathrm{~nm})^{49}$ and negative surface charge ${ }^{50}$ are paramount in meeting advanced antitumor drug-delivery demands. The morphology of nanoparticles was observed visually by TEM. PLGA and PLGA-PEG-FA were capable of self-assembling into spherical nanoparticles with a dehydrated diameter of $\sim 60-70 \mathrm{~nm}$ (Figure 2B). In contrast, Dox-loaded nanoparticles showed spherical morphology with dehydrated diameter of $\sim 40-50 \mathrm{~nm}$ (Figure $2 \mathrm{~B}$ ). Different to the diameter-change tendency measured by DLS, the diameter of Dox-loaded nanoparticles was relatively small, which may have been caused by the hydrophilic Dox encapsulation causing a more volume-compressed effect when dry than when hydrated.

\section{Hemolytic study of polymeric nanoparticles}

Despite all these advantages in size and surface properties, intravenously injected nanoparticles always show potential risk of causing serious red-cell damage, termed hemolysis activity (lysis of red blood cells). Even excessive hemolysis activity may be seriously life-threatening. ${ }^{51-54}$ Therefore, the hemolytic activity investigation is one of the most important security factors to avoid serious side effects for in vivo drug-delivery applications. Despite the practically applied polymer concentration in clinic will being extremely dilution in blood, the exaggeratedly high polymer concentration in this study was examined for insuring its sufficient security. Hemolytic images show no significant hemolysis in any polymer concentration (Figure 3, Table S1). Although hemolysis increased slightly at higher polymer concentration, hemolysis of PLGA and PLGA-PEG-FA nanoparticles was less than $5 \%$, which is regarded as nontoxic for secure in vivo applications. ${ }^{51}$ Low hemolysis reveals their favorable biocompatibility and low toxicity, even at polymeric concentrations up to $0.1 \mathrm{mg} / \mathrm{mL}$. In addition, Dox-loaded nanoparticles rarely caused obvious hemolysis increase (Figure 3). Therefore, the hemolytic results suggest that PLGA-PEG-FA is potentially feasible for targeted antitumor drug delivery through blood circulation.

\section{In vitro drug release and cellular uptake}

Owing to its broad-spectrum antitumor effects and fluorescence properties, hydrophobic Dox is one of the most popular and efficient antitumor drugs. ${ }^{55-58}$ As mentioned, Dox as the model drug can be loaded in the hydrophobic region of PLGAbased nanoparticles through interactions, ie, physical encapsulation and electrostatic attraction. Dox LE/EE in PLGA and PLGA-PEG-FA were determined to be $8.2 \% / 89.3 \%$ and $7.9 \% / 85.8 \%$, respectively (Table S2). Compared with PLGA, the slightly lower Dox-loading content in PLGAPEG-FA may be ascribed to relatively less hydrophobicity and negative charge, which is in agreement with the DLS and $\zeta$-potential tests. Subsequently, in vitro drug-release profiles of PLGA@Dox and PLGA-PEG-FA@Dox were evaluated in PBS solution. The Dox-release profile was also similar: more than $50 \%$ of the loaded Dox was release rapidly in the first 12 hours, gradually released until 36 hours, and finally reached its peak after 36 hours (Figure 4A). The similar Doxrelease profiles imply that the PEG-FA polymer-formed outer layer of nanoparticles rarely affected Dox-release behavior, which also provides a beneficial precondition for contrasting
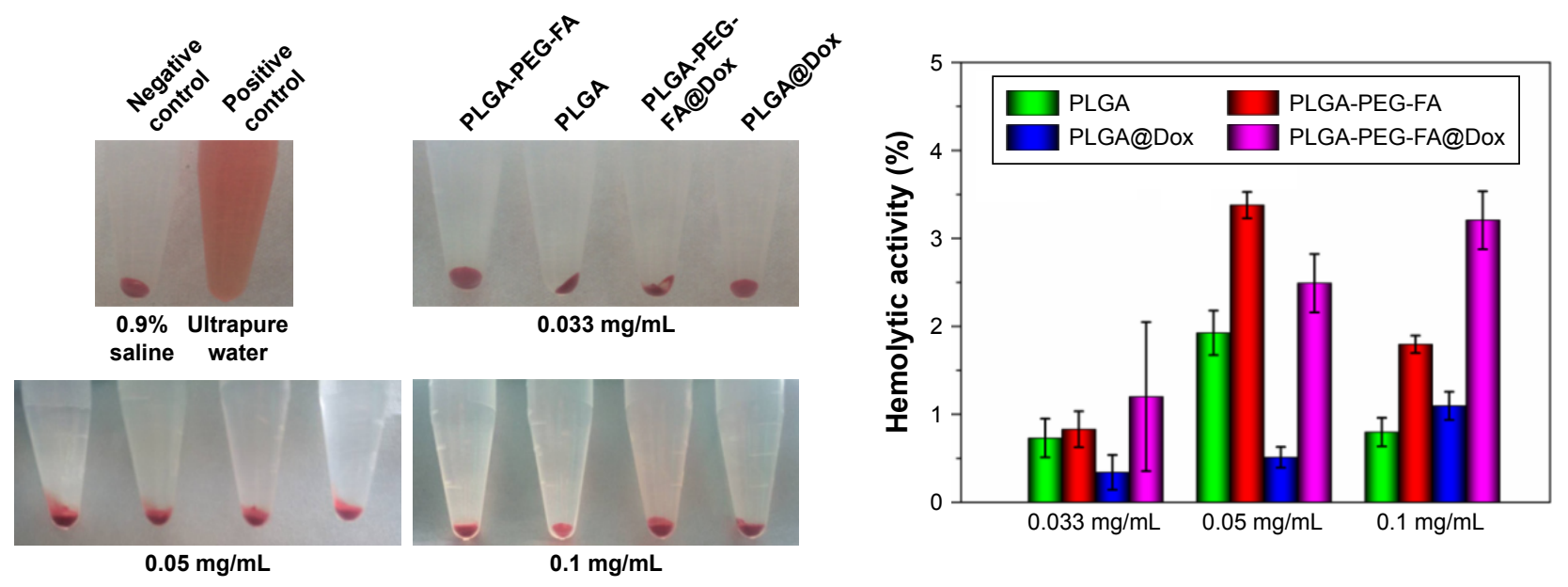

Figure 3 Hemolytic results and digital images at different polymeric concentrations. Abbreviations: PLGA, poly(lactic-co-glycolic acid); PEG, polyethylene glycol; FA, folic acid; Dox, doxorubicin. 
A

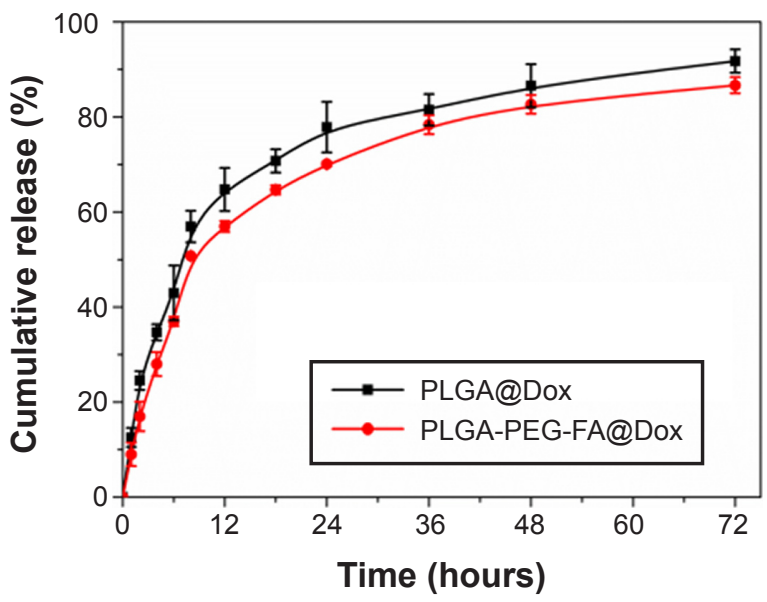

B

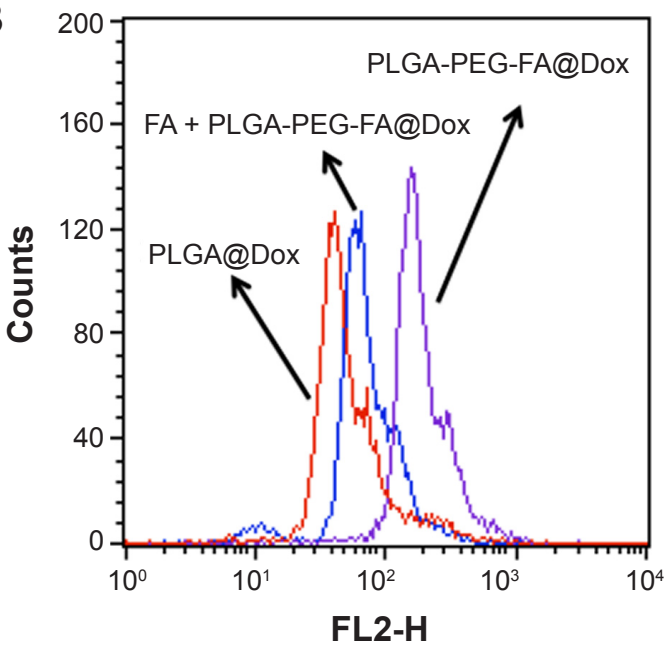

C Hoechst 33342 Phalloidin-FITC

Dox
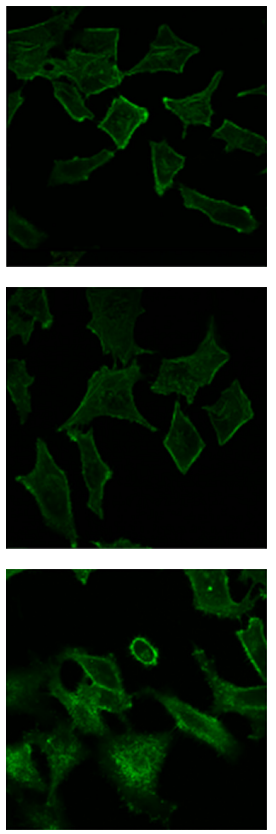
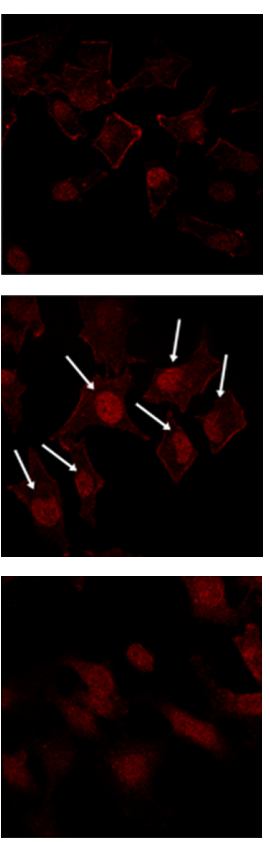

Merged
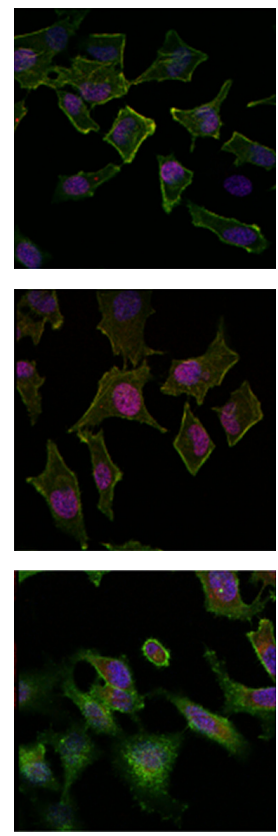

Figure 4 (A) In vitro Dox-release profiles from PLGA@Dox and PLGA-PEG-FA@Dox; (B) fluorescence-activated cell sorting of HeLa cells after 4 hours of incubation with Dox-loaded nanoparticles; $(\mathbf{C})$ confocal images $(\times 63)$ of hela cells incubated with samples for 4 hours.

Notes: Blue, hoechst 33342; green, phalloidin-FITc; red: Dox.

Abbreviations: PLGA, poly(lactic-co-glycolic acid); PEG, polyethylene glycol; FA, folic acid; Dox, doxorubicin; FITC, fluorescein isothiocyanate.

intracellular Dox-release behavior by CLSM-quantified fluorescence intensity.

Benefiting from the specific coupling of FA ligands and overexpressed FA receptors, the FA-modified carrier is capable of facilitating its retention on tumor-cell surfaces and subsequently promoting its endocytosis through time- and concentration-dependent effects. In order to evaluate cellular uptake and subsequent intracellular Dox release, intracellular Dox release from carriers was studied by visually observing fluorescence distribution in tumor cells using CLSM. Only a small amount of red fluorescence of PLGA@Dox was observed overlapping with phalloidin-FITC green fluorescence-stained cytoskeleton. Compared with PLGA@, Dox, the red fluorescence of PLGA-PEG-FA@Dox was relatively strong, which suggests more intracellular Dox released (Figure 4C). It is notable that the red fluorescence of PLGA-PEG-FA@Dox mainly overlapped with Hoechst 33342 blue fluorescence-stained cell nuclei. To confirm the enhanced intracellular drug-delivery phenomenon was caused by FA-mediated target effect but not PEG-block influence, PLGA-PEG-FA@Dox was cocultured with FA receptors to block HeLa cells using another control sample. 

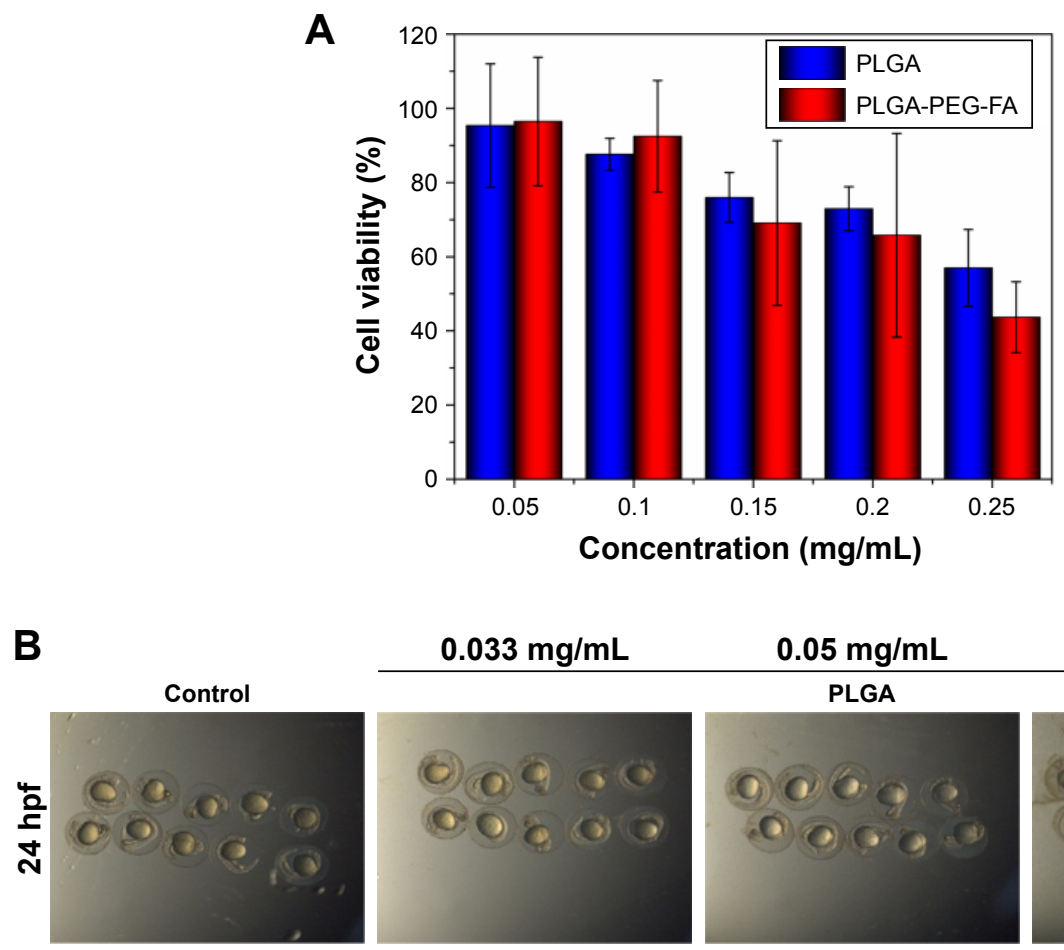

$0.1 \mathrm{mg} / \mathrm{mL}$
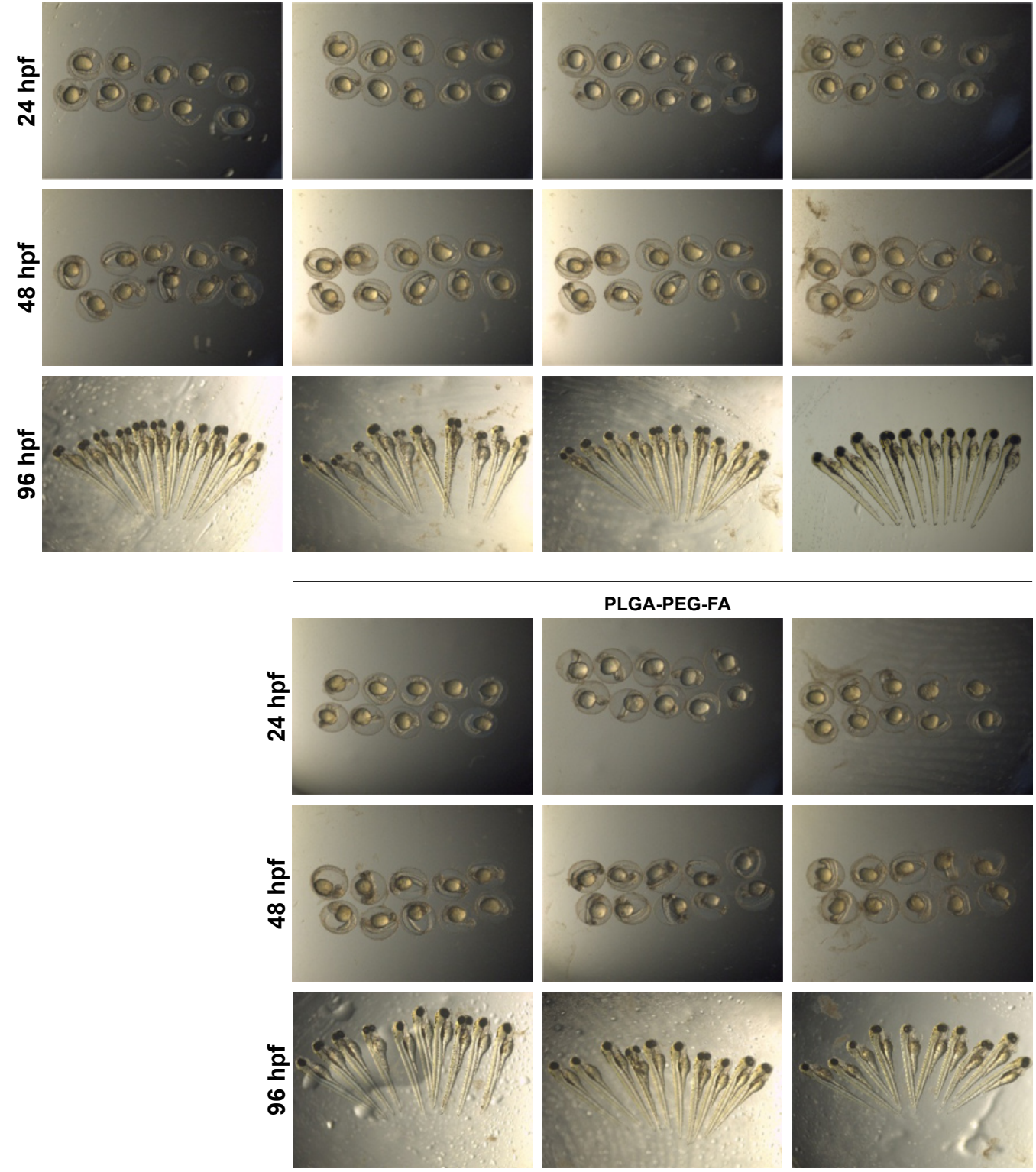

Figure 5 (A) Cell viability at different polymer concentrations; (B) concentration- and time-dependent toxicity of PLGA and PLGA-PEG-FA nanoparticles on zebrafish embryos and larvae.

Abbreviations: PLGA, poly(lactic-co-glycolic acid); PEG, polyethylene glycol; FA, folic acid; hpf, hours postfertilization. 
Compared to PLGA-PEG-FA@Dox, red fluorescence of FA-pretreated PLGA-PEG-FA@Dox was relatively weaker, and mostly overlapped with phalloidin-FITC green fluorescence-stained cytoskeleton. To confirm enhanced PLGA-PEG-FA@Dox internalization by tumor cells, intracellular Dox content released from carriers was detected by FACS quantification. The results demonstrated that the intracellular Dox-fluorescence intensity of PLGA-PEG-FA@ Dox was several times higher than the control group, which was consistent with the CLSM determination (Figure 4B). As such, the FACS and CLSM results both indicated that PLGA-PEG-FA@Dox was preferentially endocytosed by tumor cells and subsequently enhanced intracellular Dox release. After 24 hours' incubation, more strong Dox red fluorescence of all samples was detected, and focused on Hoechst 33342 blue fluorescence-stained cell nuclei to induce tumor-cell apoptosis (Figure S3).

\section{Cytotoxicity and biocompatibility}

To verify biocompatibility and cytotoxicity, a series of polymeric nanoparticles with different concentrations were cocultured with HeLa cells for 48 hours. At polymer concentrations lower than $0.1 \mathrm{mg} / \mathrm{mL}$, acceptable cell viability $(>80 \%)$ of PLGA and PLGA-PEG-FA revealed low toxicity (Figure 5A), which has been identified to meet adequate security standards for biomedical applications. ${ }^{59-63} \mathrm{With}$ polymerconcentration increase, cell viability reduced gradually, exhibiting concentration-dependent cytotoxicity. Toxicity to zebrafish development was also investigated to confirm the security of these polymeric nanoparticles at a relatively high concentration $(0.1 \mathrm{mg} / \mathrm{mL})$. No serious malformation or death was observed at the embryo-development stage or for hatched zebrafish larva, implying reliable security in zebrafish development (Figures 5B and S4). These toxicity studies confirm that targeted modification by PEG-FA block will not lead to additional toxicity, showing favorable biocompatibility. Despite the applied polymeric concentration being far lower than $0.1 \mathrm{mg} / \mathrm{mL}$ under extreme blood dilution during antitumor drug delivery, systemic investigation of the security of the operating concentration of PLGA-PEG-FA can provide particularly important clues for biomedicine design and application.

\section{Conclusion}

In conclusion, a facile modification of biodegradable polymeric nanoparticles with a dual tumor target, ie, EPR, resulting in a passive target and an FA-mediated positive target, was studied for use as a secure and efficient nanocarrier for further improving antitumor drug delivery. Successful modification of PLGA-PEG-FA was confirmed by ${ }^{1} \mathrm{H}$ NMR measurement. In aqueous solution, PLGA-PEG-FA was able to self-assemble into nanoparticles with hydrodynamic diameter around $100 \mathrm{~nm}$ and negative surface charge, which was desirable to meet the demands of advanced antitumorcarrier design. Enhanced internalization of Dox-loaded PLGA-PEG-FA nanoparticles by FA receptors in overexpressed tumor cells was proved by CLSM and FACS investigations, revealing favorable efficacy. In addition, hemolysis, MTS, and zebrafish-development results confirmed the formulation's security in biomedical applications, even at polymeric concentrations up to $0.1 \mathrm{mg} / \mathrm{mL}$. Therefore, these dual tumor-targeted PLGA-PEG-FA nanoparticles could be a feasible nanocarrier for secure and efficient antitumor drug delivery.

\section{Acknowledgments}

This work was supported by the National Natural Science Foundation of China (51603023), Fundamental Research Funds for the National Key R\&D Project (2016YFC1102305), Fundamental Research Funds for Central Universities (106112016CDJXY230002), China Postdoctoral Science Foundation (2016M602656, 2017T100682), the Chongqing Research Program of Basic research and Frontier Technology (cstc2017jcyjAX0186), and the Chongqing Postdoctoral Scientific Research Foundation (Xm2016011).

\section{Disclosure}

The authors report no conflicts of interest in this work.

\section{References}

1. Luten J, van Nostruin CF, De Smedt SC, Hennink WE. Biodegradable polymers as non-viral carriers for plasmid DNA delivery. J Control Release. 2008;126(2):97-110.

2. Li YL, Maciel D, Rodrigues J, Shi XY, Tomas H. Biodegradable polymer nanogels for drug/nucleic acid delivery. Chem Rev. 2015; 115(16):8564-8608.

3. Wang N, Wang Z, Nie S, et al. Biodegradable polymeric micelles coencapsulating paclitaxel and honokiol: a strategy for breast cancer therapy in vitro and in vivo. Int J Nanomedicine. 2017;12:1499-1514.

4. Nair LS, Laurencin CT. Biodegradable polymers as biomaterials. Prog Polym Sci. 2007;32(8-9):762-798.

5. Wu W, Wang WG, Li JS. Star polymers: advances in biomedical applications. Prog Polym Sci. 2015;46:55-85.

6. Lammers T, Aime S, Hennink WE, Storm G, Kiessling F. Theranostic nanomedicine. Accounts Chem Res. 2011;44(10):1029-1038.

7. Ha CS, Gardella JA. Surface chemistry of biodegradable polymers for drug delivery systems. Chem Rev. 2005;105(11):4205-4232.

8. Nicolas J, Mura S, Brambilla D, Mackiewicz N, Couvreur P. Design, functionalization strategies and biomedical applications of targeted biodegradable/biocompatible polymer-based nanocarriers for drug delivery. Chem Soc Rev. 2013;42(3):1147-1235. 
9. Tian HY, Tang ZH, Zhuang XL, Chen XS, Jing XB. Biodegradable synthetic polymers: preparation, functionalization and biomedical application. Prog Polym Sci. 2012;37(2):237-280.

10. Veiseh O, Gunn JW, Zhang MQ. Design and fabrication of magnetic nanoparticles for targeted drug delivery and imaging. Adv Drug Deliv Rev. 2010;62(3):284-304.

11. Arap W, Pasqualini R, Ruoslahti E. Cancer treatment by targeted drug delivery to tumor vasculature in a mouse model. Science. 1998; 279(5349):377-380.

12. Murthy N, Campbell J, Fausto N, Hoffman AS, Stayton PS. Design and synthesis of $\mathrm{pH}$-responsive polymeric carriers that target uptake and enhance the intracellular delivery of oligonucleotides. J Control Release. 2003;89(3):365-374.

13. Mura S, Nicolas J, Couvreur P. Stimuli-responsive nanocarriers for drug delivery. Nat Mater. 2013;12(11):991-1003.

14. Ehrhardt C, Kneuer C, Bakowsky U. Selectins: an emerging target for drug delivery. Adv Drug Deliver Rev. 2004;56(4):527-549.

15. Bimbo LM, Sarparanta M, Santos HA, et al. Biocompatibility of thermally hydrocarbonized porous silicon nanoparticles and their biodistribution in rats. ACS Nano. 2010;4(6):3023-3032.

16. Wu W, Zhang Q, Wang J, et al. Tumor-targeted aggregation of $\mathrm{pH}-$ sensitive nanocarriers for enhanced retention and rapid intracellular drug release. Polym Chem. 2014;5(19):5668-5679.

17. He QJ, Shi JL. MSN anti-cancer nanomedicines: chemotherapy enhancement, overcoming of drug resistance, and metastasis inhibition. Adv Mater. 2014;26(3):391-411.

18. Dellian M, Yuan F, Trubetskoy VS, Torchilin VP, Jain RK. Vascular permeability in a human tumour xenograft: molecular charge dependence. Br J Cancer. 2000;82(9):1513-1518.

19. Hambley TW. Physiological targeting to improve anticancer drug selectivity. Aust J Chem. 2008;61(9):647-653.

20. Zhang HB, Liu DF, Shahbazi MA, et al. Fabrication of a multifunctional nano-in-micro drug delivery platform by microfluidic templated encapsulation of porous silicon in polymer matrix. Adv Mater. 2014; 26(26):4497-4503.

21. Lee ES, Gao ZG, Bae YH. Recent progress in tumor $\mathrm{pH}$ targeting nanotechnology. J Control Release. 2008;132(3):164-170.

22. Jiang QY, Lai LH, Shen J, Wang QQ, Xu FJ, Tang GP. Gene delivery to tumor cells by cationic polymeric nanovectors coupled to folic acid and the cell-penetrating peptide octaarginine. Biomaterials. 2011;32(29): $7253-7262$.

23. Lee KY, Seow E, Zhang Y, Lim YC. Targeting CCL21-folic acidupconversion nanoparticles conjugates to folate receptor- $\alpha$ expressing tumor cells in an endothelial-tumor cell bilayer model. Biomaterials 2013;34(20):4860-4871.

24. Li JC, Hu Y, Yang J, et al. Facile synthesis of folic acid-functionalized iron oxide nanoparticles with ultrahigh relaxivity for targeted tumor MR imaging. J Mater Chem B Mater Biol Med. 2015;3(28):5720-5730.

25. Zhang GL, Gao JL, Qian JC, et al. Hydroxylated mesoporous nanosilica coated by polyethylenimine coupled with gadolinium and folic acid: a tumor-targeted T1 magnetic resonance contrast agent and drug delivery system. ACS Appl Mater Interfaces. 2015;7(26):14192-14200.

26. Yin F, Zhang BT, Zeng SW, et al. Folic acid-conjugated organically modified silica nanoparticles for enhanced targeted delivery in cancer cells and tumor in vivo. J Mater Chem B Mater Biol Med. 2015;3(29): 6081-6093.

27. Lammers T, Kiessling F, Hennink WE, Storm G. Drug targeting to tumors: principles, pitfalls and (pre-) clinical progress. J Control Release. 2012;161(2):175-187.

28. Devulapally R, Foygel K, Sekar TV, Willmann JK, Paulmurugan R. Gemcitabine and antisense-microRNA co-encapsulated PLGA-PEG Polymer nanoparticles for hepatocellular carcinoma therapy. ACS Appl Mater Interfaces. 2016;8(49):33412-33422.

29. Kamaly N, Yameen B, Wu J, Farokhzad OC. Degradable controlledrelease polymers and polymeric nanoparticles: mechanisms of controlling drug release. Chem Rev. 2016;116(4):2602-2663.
30. Hines DJ, Kaplan DL. Poly(lactic-co-glycolic) acid-controlled-release systems: experimental and modeling insights. Crit Rev Ther Drug Carrier Syst. 2013;30(3):257-276.

31. Hu CM, Fang RH, Wang KC, et al. Nanoparticle biointerfacing by platelet membrane cloaking. Nature. 2015;526(7571):118-121.

32. Dehaini D, Fang RH, Luk BT, et al. Ultra-small lipid-polymer hybrid nanoparticles for tumor-penetrating drug delivery. Nanoscale. 2016; 8(30):14411-14419.

33. Devulapally R, Paulmurugan R. Polymer nanoparticles for drug and small silencing RNA delivery to treat cancers of different phenotypes. Wiley Interdiscip Rev Nanomed Nanobiotechnol. 2014;6(1):40-60.

34. Wang TY, Choe JW, Pu KY, et al. Ultrasound-guided delivery of microRNA loaded nanoparticles into cancer. J Control Release. 2015; 203:99-108

35. Zhang XD, Zeng XW, Liang X, et al. The chemotherapeutic potential of PEG-b-PLGA copolymer micelles that combine chloroquine as autophagy inhibitor and docetaxel as an anti-cancer drug. Biomaterials. 2014;35(33):9144-9154.

36. Yoneki N, Takami T, Ito T, et al. One-pot facile preparation of PEGmodified PLGA nanoparticles: effects of PEG and PLGA on release properties of the particles. Colloids Surf A Physicochem Eng Asp. 2015;469:66-72.

37. Cheng J, Teply BA, Sherifi I, et al. Formulation of functionalized PLGAPEG nanoparticles for in vivo targeted drug delivery. Biomaterials. 2007;28(5):869-876.

38. Luo CQ, Xing L, Cui PF, et al. Curcumin-coordinated nanoparticles with improved stability for reactive oxygen species-responsive drug delivery in lung cancer therapy. Int J Nanomedicine. 2017;12:855-869.

39. Rafiei P, Haddadi A. Docetaxel-loaded PLGA and PLGA-PEG nanoparticles for intravenous application: pharmacokinetics and biodistribution profile. Int J Nanomedicine. 2017;12:935-947.

40. Fan L, Li F, Zhang HT, et al. Co-delivery of PDTC and doxorubicin by multifunctional micellar nanoparticles to achieve active targeted drug delivery and overcome multidrug resistance. Biomaterials. 2010;31(21): 5634-5642.

41. Kataoka K, Matsumoto T, Yokoyama M, et al. Doxorubicin-loaded poly(ethylene glycol)-poly( $\beta$-benzyl-1-aspartate) copolymer micelles: their pharmaceutical characteristics and biological significance. J Control Release. 2000;64(1-3):143-153.

42. Wu W, Chen M, Wang J, et al. Nanocarriers with dual $\mathrm{pH}$-sensitivity for enhanced tumor cell uptake and rapid intracellular drug release. RSC Adv. 2014;4(58):30780-30783.

43. Yue ZG, You ZX, Yang QZ, et al. Molecular structure matters: PEG-bPLA nanoparticles with hydrophilicity and deformability demonstrate their advantages for high-performance delivery of anti-cancer drugs. J Mater Chem B Mater Biol Med. 2013;1(26):3239-3247.

44. Wu W, Wang JT, Lin ZF, Li XH, Li JS. Tumor-acidity activated surface charge-conversion of polymeric nanocarriers for enhanced cell adhesion and targeted drug release. Macromol Rapid Commun. 2014;35(19): 1679-1684.

45. Wang WW, Deng LD, Xu SX, et al. A reconstituted "two into one" thermosensitive hydrogel system assembled by drug-loaded amphiphilic copolymer nanoparticles for the local delivery of paclitaxel. J Mater Chem B Mater Biol Med. 2013;1(4):552-563.

46. Acharya S, Sahoo SK. PLGA nanoparticles containing various anticancer agents and tumour delivery by EPR effect. Adv Drug Deliv Rev. 2011;63(3):170-183.

47. Hamdy S, Haddadi A, Hung RW, Lavasanifar A. Targeting dendritic cells with nano-particulate PLGA cancer vaccine formulations. $A d v$ Drug Deliv Rev. 2011;63(10-11):943-955.

48. Danhier F, Ansorena E, Silva JM, Coco R, Le Breton A, Preat V. PLGA-based nanoparticles: an overview of biomedical applications. $J$ Control Release. 2012;161(2):505-522.

49. Wang JQ, Mao WW, Lock LL, et al. The role of micelle size in tumor accumulation, penetration, and treatment. ACS Nano. 2015;9(7): 7195-7206. 
50. Duan XP, Li YP. Physicochemical characteristics of nanoparticles affect circulation, biodistribution, cellular internalization, and trafficking. Small. 2013;9(9-10):1521-1532.

51. Fischer D, Li YX, Ahlemeyer B, Krieglstein J, Kissel T. In vitro cytotoxicity testing of polycations: influence of polymer structure on cell viability and hemolysis. Biomaterials. 2003;24(7): 1121-1131.

52. Wei YM, Liang J, Zheng XL, et al. Lung-targeting drug delivery system of baicalin-loaded nanoliposomes: development, biodistribution in rabbits, and pharmacodynamics in nude mice bearing orthotopic human lung cancer. Int J Nanomedicine. 2017;12:251-261.

53. Kinosita K, Tsong TY. Hemolysis of human erythrocytes by a transient electric-field. Proc Natl Acad Sci U S A. 1977;74(5):1923-1927.

54. Hsu LL, Champion HC, Campbell-Lee SA, et al. Hemolysis in sickle cell mice causes pulmonary hypertension due to global impairment in nitric oxide bioavailability. Blood. 2007;109(7):3088-3098.

55. Wu W, Ye CY, Xiao H, et al. Hierarchical mesoporous silica nanoparticles for tailorable drug release. Int J Pharm. 2016;511(1):65-72.

56. Chen TC, Wu W, Xiao H, Chen YX, Chen M, Li JS. Intelligent drug delivery system based on mesoporous silica nanoparticles coated with an ultra-pH-sensitive gatekeeper and poly(ethylene glycol). ACS Macro Lett. 2016;5(1):60-63.
57. Li S, Zhao ZX, Wu W, Ding CM, Li JS. Dual pH-responsive micelles with both charge-conversional property and hydrophobic-hydrophilic transition for effective cellular uptake and intracellular drug release. Polym Chem. 2016;7(12):2202-2208.

58. Wu ZZ, Cai MT, Cao J, Zhang JX, Luo XL. Effects of copolymer component on the properties of phosphorylcholine micelles. Int $J$ Nanomedicine. 2017;12:487-500.

59. Nel A, Xia T, Meng H, et al. Nanomaterial toxicity testing in the $21 \mathrm{st}$ century: use of a predictive toxicological approach and high-throughput screening. Acc Chem Res. 2013;46(3):607-621.

60. Zhou T, Dong Q, Shen Y, et al. PEG-b-PCL polymeric nano-micelle inhibits vascular angiogenesis by activating p53-dependent apoptosis in zebrafish. Int J Nanomedicine. 2016;11:6517-6531.

61. Zhu MT, Nie GJ, Meng H, Xia T, Nel A, Zhao YL. Physicochemical properties determine nanomaterial cellular uptake, transport, and fate. Acc Chem Res. 2013;46(3):622-631.

62. Kim ST, Saha K, Kim C, Rotello VM. The role of surface functionality in determining nanoparticle cytotoxicity. Acc Chem Res. 2013;46(3): 681-691.

63. Rizzo LY, Golombek SK, Mertens ME, et al. In vivo nanotoxicity testing using the zebrafish embryo assay. J Mater Chem B Mater Biol Med. 2013;1(32):3918-3925. 


\section{Supplementary materials}

A
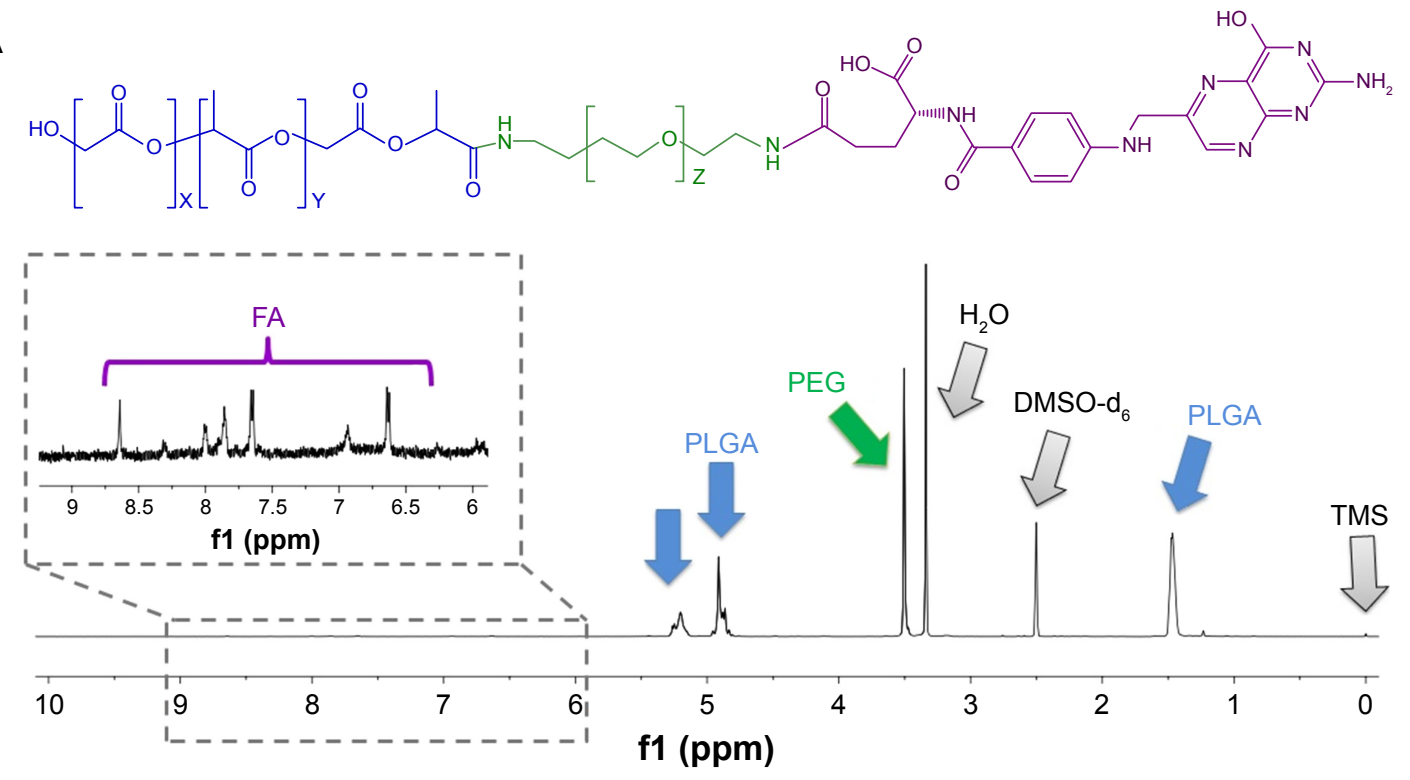

B

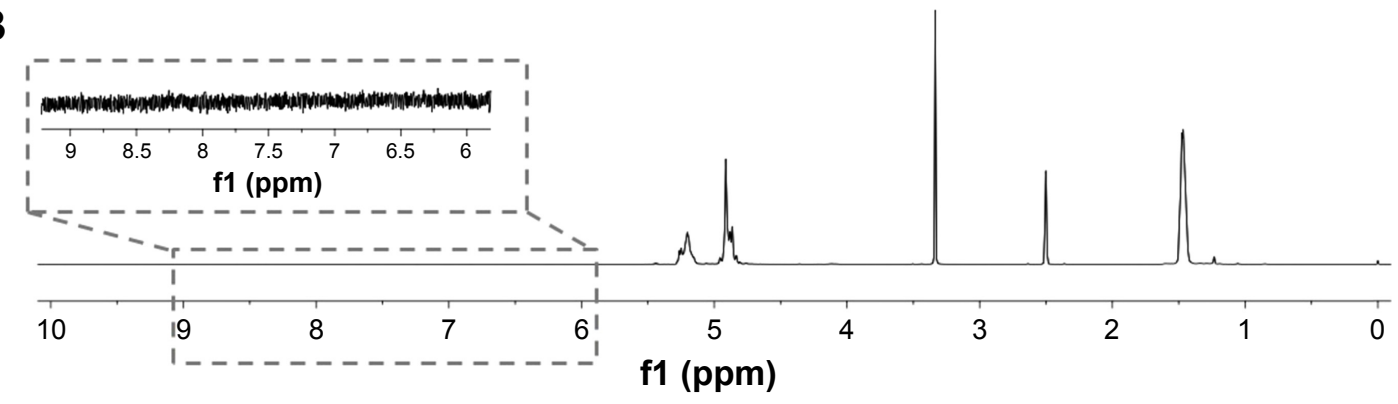

Figure SI 'H NMR spectra of PLGA-PEG-FA (A) and PLGA (B) in DMSO-d.

Abbreviations: NMR, nuclear magnetic resonance; PLGA, poly(lactic-co-glycolic acid); PEG, polyethylene glycol; FA, folic acid; DMSO, dimethyl sulfoxide; TMS, tetramethylsilane. 

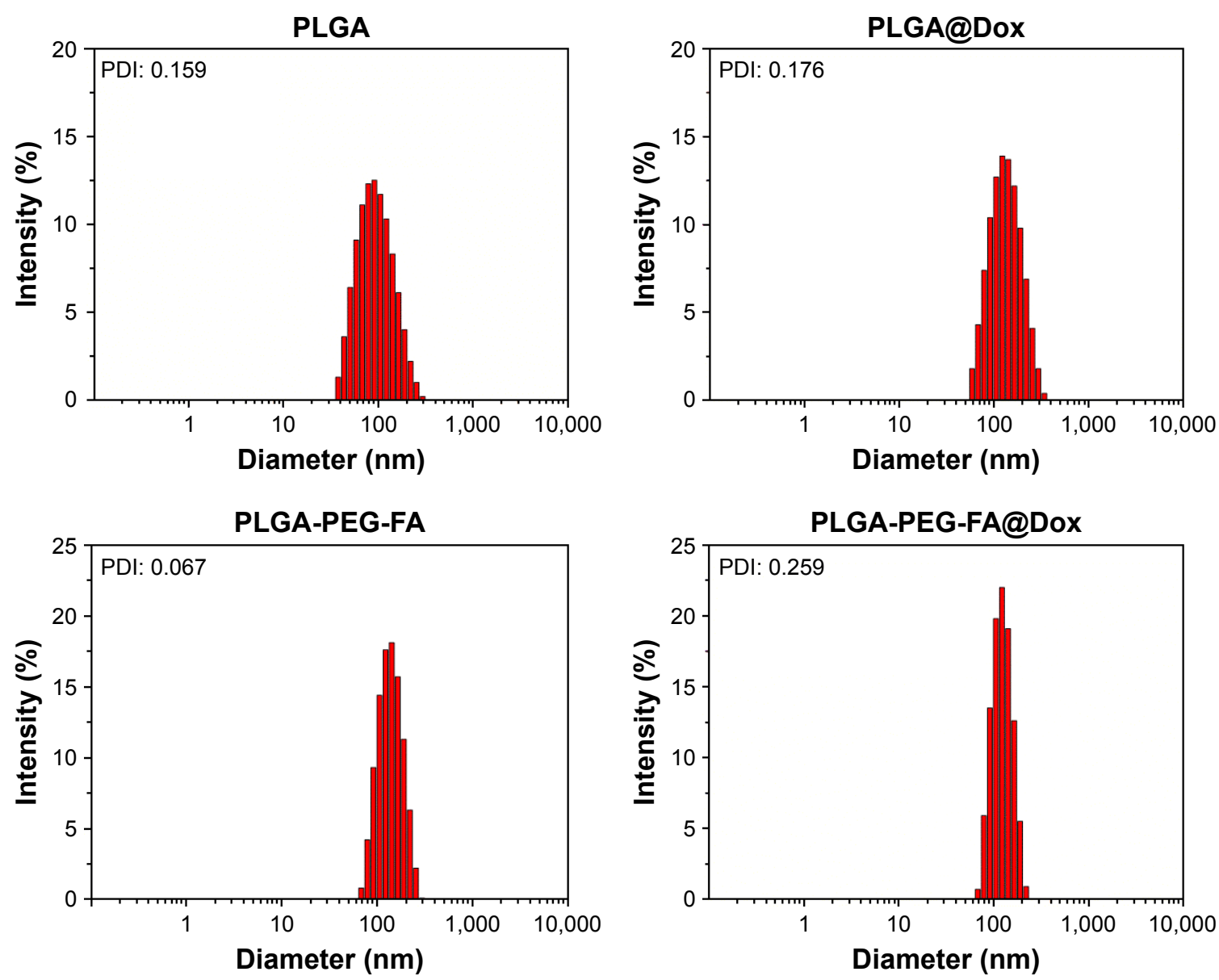

Figure S2 Size distribution of nanoparticles at a concentration of $0.5 \mathrm{mg} / \mathrm{mL}$.

Abbreviations: PLGA, poly(lactic-co-glycolic acid); PEG, polyethylene glycol; FA, folic acid; Dox, doxorubicin.

Table SI Hemolysis ratios caused by nanoparticles

\begin{tabular}{llll}
\hline Sample & Hemolysis ratio (\%) & & $\mathbf{0 . 1} \mathbf{~ m g} / \mathbf{m L}$ \\
\cline { 2 - 4 } & $\mathbf{0 . 0 3 3} \mathbf{~ m g / m L}$ & $\mathbf{0 . 0 5} \mathbf{~ m g / m L}$ & $0.8 \pm 0.16$ \\
\hline PLGA & $0.73 \pm 0.22$ & $1.93 \pm 0.25$ & $1.8 \pm 0.1$ \\
PLGA-PEG-FA & $0.83 \pm 0.2$ & $3.38 \pm 0.15$ & $1.1 \pm 0.16$ \\
PLGA@Dox & $0.34 \pm 0.2$ & $0.51 \pm 0.19$ & $3.21 \pm 0.33$ \\
PLGA-PEG-FA@Dox & $1.22 \pm 0.85$ & $2.5 \pm 0.33$ & \\
\hline
\end{tabular}

Abbreviations: PLGA, poly(lactic-co-glycolic acid); PEG, polyethylene glycol; FA, folic acid; Dox, doxorubicin.

Table S2 Summary of Dox content loaded in nanoparticles

\begin{tabular}{llll}
\hline Sample & Polymer/drug (w/w) & LE (\%) & EE (\%) \\
\hline PLGA@Dox & $10: 1$ & 8.2 & 89.3 \\
PLGA-PEG-FA@Dox & $10: 1$ & 7.9 & 85.8 \\
\hline
\end{tabular}

Abbreviations: PLGA, poly(lactic-co-glycolic acid); PEG, polyethylene glycol; FA, folic acid; Dox, doxorubicin; LE, loading efficiency; EE, encapsulation efficiency. 


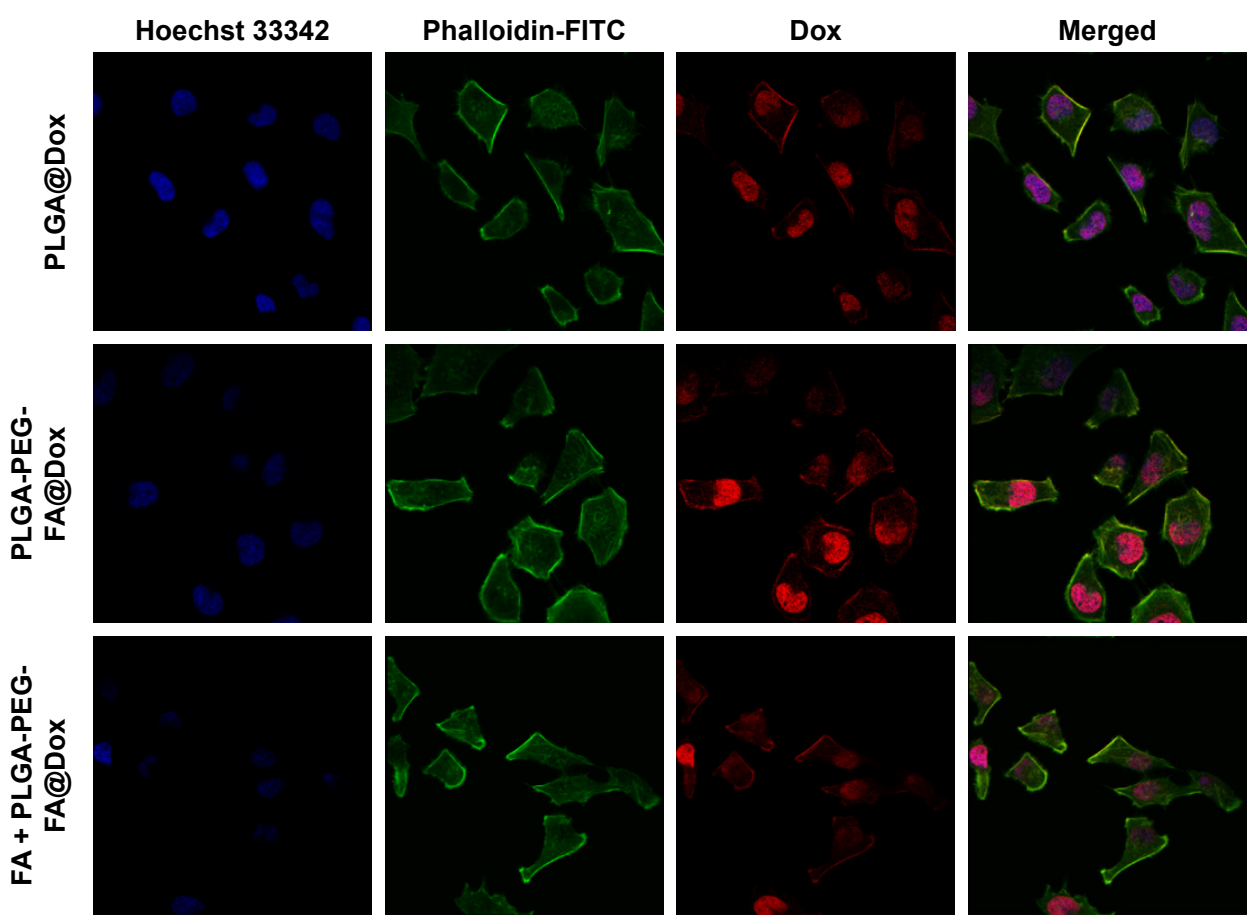

Figure S3 Confocal images $(\times 63)$ of HeLa cells incubated with samples for 24 hours.

Notes: Blue, hoechst 33342; green, phalloidin-FITC; red, Dox.

Abbreviations: PLGA, poly(lactic-co-glycolic acid); PEG, polyethylene glycol; FA, folic acid; Dox, doxorubicin; FITC, fluorescein isothiocyanate.

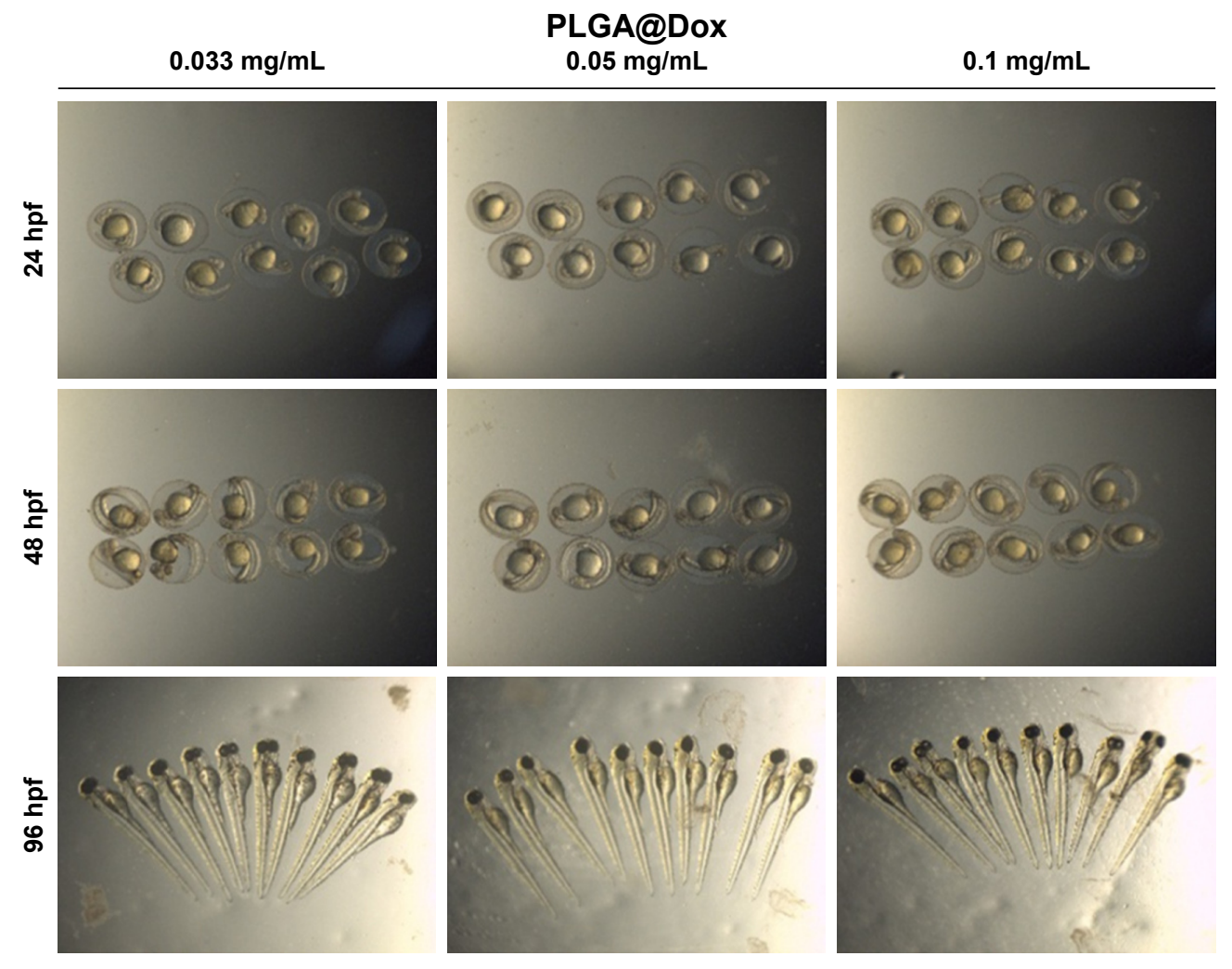

Figure S4 (Continued) 


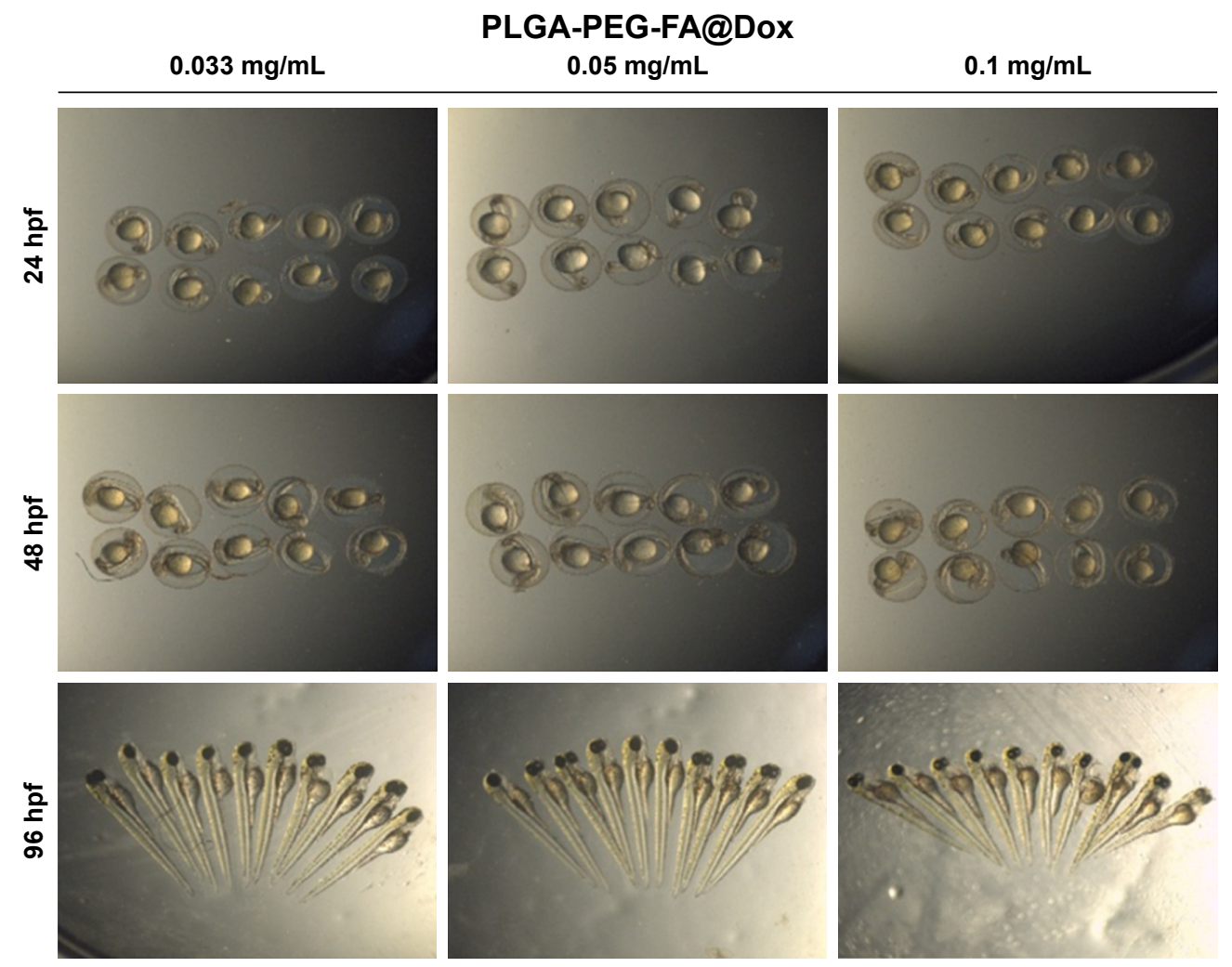

Figure S4 Concentration- and time-dependent toxicity studies of Dox-loaded polymer nanoparticles on zebrafish embryos and larvae.

Abbreviations: PLGA, poly(lactic-co-glycolic acid); PEG, polyethylene glycol; FA, folic acid; Dox, doxorubicin; hpf, hours postfertilization.

\section{Publish your work in this journal}

The International Journal of Nanomedicine is an international, peerreviewed journal focusing on the application of nanotechnology in diagnostics, therapeutics, and drug delivery systems throughout the biomedical field. This journal is indexed on PubMed Central, MedLine, CAS, SciSearch $®$, Current Contents ${ }^{\circledR} /$ Clinical Medicine,
Journal Citation Reports/Science Edition, EMBase, Scopus and the Elsevier Bibliographic databases. The manuscript management system is completely online and includes a very quick and fair peer-review system, which is all easy to use. Visit http://www.dovepress.com/ testimonials.php to read real quotes from published authors. 